\title{
VARIA MIRANDESCA. ATRIBUCIONES Y ÚLTIMAS NOVEDADES SOBRE LA PINTURA DE JUAN DE MIRANDA (1723-1805)*
}

\author{
Juan Alejandro Lorenzo Lima** \\ Universidad Europea de Canarias
}

\section{RESUMEN}

El artículo resume las novedades surgidas durante los últimos años en torno al pintor Juan de Miranda, destacando algunas propuestas de atribución sobre lienzos que formaron parte de exposiciones temporales promovidas en Gran Canaria y otros conocidos en distinto modo que exhiben ya el museo de arte sacro y la parroquia de Teguise (Lanzarote). Se mencionan también algunas obras que han podido documentarse en Fuerteventura, así como retratos que conservan varios particulares de Tenerife y guardan relación con su producción tardía. Al margen de dos pinturas de temática sacra que son reproducidas por primera vez, el artículo da a conocer una representación inédita de la Virgen del Rosario que se le atribuye ahora y proviene de una colección de Alicante. Este descubrimiento es notable y permite avanzar en el estudio de la etapa peninsular del autor, la más desconocida en su trayectoria vital y profesional.

Palabras clave: pintura, Juan de Miranda, siglo xvini, Canarias.

\section{VARIA MIRANDESCA. ATTRIBUTIONS AND LAST NOTES ABOUT THE PAINTING OF JUAN DE MIRANDA (1723-1805)}

\section{Abstract}

The essay aims to summarize the news released about the painter Juan de Miranda in the last years, highlighting some attribution proposals on canvases that were part of temporary exhibitions promoted in Gran Canaria and others known in different ways that already exhibit permanently the museum of sacred art and the parish of Teguise (Lanzarote). Also mentioned are some works that have been documented in Fuerteventura, as well as portraits that conserve several collectors in Tenerife and are related to their late production. Apart from two paintings of sacred themes that are reproduced for the first time, the article presents an unknown representation of the Virgen del Rosario that is now attributes to him and comes from a collection in Alicante. This discovery is remarkable and allows advancing in the study of the peninsular stage of the aythor, the most unknown in his life and career.

Keywords: Painting, Juan de Miranda, $18^{\text {th }}$ century, Canary Island. 
El arte de Juan Ventura de Miranda y Cejas (1723-1805) resume los cambios que la pintura experimentó en Canarias a finales del Antiguo Régimen, aunque ese hecho no se reconoce a veces como tal y motiva diferentes propuestas de análisis. Con su estilo, renovador en el fondo y moderno en las formas, supo aproximarse al ideario más selecto de aquel tiempo, el mismo que perseguía la regeneración de las artes conforme a los dictados de la Academia de San Fernando y el idealismo que tanto defendieron sus docentes e impulsores ${ }^{1}$. Sin embargo, como otros episodios que conciernen al Archipiélago durante el periodo de la Ilustración, el estudio de tal coyuntura no deja de ser paradójico o susceptible de interpretaciones contradictorias. El mayor problema que atañe a este autor radica en calibrar adecuadamente el alcance de su trabajo, no sólo en lo que se refiere al ejercicio artístico o profesional con un carácter localista².

Miranda no es un pintor secundario de la periferia española del siglo XviıI y, aunque sus acciones parecen a veces desconcertantes, despiertan el interés necesario para afrontar un nuevo estudio de caso con lo que ya es conocido de su biografía. Pocos maestros de ese tiempo vivieron de forma intensa la época en que se inscribe su labor cotidiana con los pinceles, de modo que nuestro artífice, algo mitificado en los opúsculos biográficos del Ochocientos, no fue un creador atípico ni extravagante como hizo ver Millares Torres ${ }^{3}$. Basta recordar que tuvo problemas de todo tipo por los primeros años de vida licenciosa en La Laguna, sufrió un encarcelamiento en el norte de África a causa de ello ${ }^{4}$, no ganaba premio en los certámenes de la Academia a pesar del buen acabado de la pintura que envió a Madrid en $1760^{5}$, protagonizaría un viaje de larga duración por tierras peninsulares y después del regreso definitivo a las Islas, ya con un bagaje notable, intentó enmendar ese pasado con acciones que redundaron en el reconocimiento social y profesional que tuvo al tiempo de morir en 1805. No cabe duda de que su trayectoria quedó determinada por dichos acontecimientos y otros de índole familiar, pero también por actividades en auge que, como la pesca o la docencia particular del arte, condicionaron una existencia que superó las cinco décadas de trabajo frente al caballete y estuvo supeditada a una

\footnotetext{
* Este artículo se enmarca en acciones desarrolladas por el grupo de investigación Arquitectura y desarrollo turistico sostenible [Universidad Europea de Canarias, Tenerife].

**E-mail: juanalejandro.lorenzo@universidadeuropea.es.

1 Úbeda de los Cobos, Andrés: Pensamiento artístico español del siglo XVIII, Madrid, 2001.

2 Para un conocimiento del autor y su producción es de obligada lectura la monografía de Rodríguez González, Margarita: Juan de Miranda [catálogo de la exposición homónima], Santa Cruz de Tenerife, 1994, donde se da cuenta de la bibliografía previa.

3 Millares Torres, Agustín: Biografías de canarios célebres, Las Palmas de Gran Canaria, 1982, t. I, pp. 197-201.

${ }^{4}$ SuÁrez Grimón, Vicente: «El envío del pintor Juan de Miranda al presidio de Orán: un reflejo de la crisis de la Audiencia de Canarias en el siglo XviıI", Anuario de Estudios Atlánticos, n. ${ }^{\circ}$ 54-t. II (2008), pp. 265-296.

5 Lorenzo Lima, Juan Alejandro: «Juan de Miranda en la Academia. El artista y su participación en el concurso de pintura de 1760», Estudios Canarios. Anuario del Instituto de Estudios Canarios, n. ${ }^{\circ} 60$ (2011), pp. 173-206.
} 
itinerancia no regular entre las islas de Fuerteventura, Lanzarote, Gran Canaria y, sobre todo, Tenerife ${ }^{6}$.

La experiencia del viaje tras el presidio de Orán es clave a la hora de comprender la evolución que su estilo experimentó luego, porque, salvo el caso de Gaspar de Quevedo (1616-1670...) en el siglo precedente, nunca antes un pintor nacido en las Islas tuvo un contacto directo con lo sucedido en ciudades peninsulares para renovar su concepción o forma de entender el arte. El retorno al Archipiélago durante la década de 1770 marca un hito en ese sentido, ya que sirve de estímulo a la hora de valorar los progresos que su pintura experimentó en cuestiones conceptuales (forma de componer en base a grabados y estampas contemporáneas) y propiamente artísticas (técnica peculiar que traduce el modo de "pintar con pinceladas», tan en boga entonces). Sin embargo, quienes regían los derroteros de la política insular no supieron ni quisieron ver las novedades que su obra aportaba en aquellos momentos. Por esa razón sorprende que, al debatir sobre el estado de las artes en el seno de la Real Sociedad Económica de Amigos del País de Tenerife después de 1777, sus miembros obviaran el trabajo acometido por Miranda en Santa Cruz y otros pueblos del norte de la Isla ${ }^{7}$.

El bagaje aludido, inalcanzable para muchos desde la perspectiva isleńa, es fundamental a la hora de describir las creaciones de este artífice y no se resalta lo suficiente al estudiar algunas pinturas importantes, sobre todo las que guardan relación con su periplo peninsular. A esa coyuntura se aludirá en otro epígrafe para contextualizar una Virgen del Rosario que proviene de Alicante y no dudamos en atribuirle [fig. 1], pero es oportuno volver sobre asuntos primordiales. Aspectos poco explorados hasta ahora como el idealismo latente en su producción, la aproximación a teorizaciones sobre lo bello que exaltó Anton Raphael Mengs (1728-1799), el sentido otorgado a los retratos como figuración personal e irrepetible de cada individuo, o el modo de componer y valorar las representaciones sagradas, entre otros, merecen un estudio contextual que supere lo ya expuesto, huyendo de los tópicos y abriendo nuevas posibilidades de análisis.

Retomar el estudio del artista es una necesidad inexcusable en nuestro tiempo, gracias, sobre todo, a últimos planteamientos que se han manifestado para ello en los ámbitos peninsular y americano. A medio camino entre ambas realidades, Miranda asume como propios los cambios que la pintura de aquel periodo revelaban en una tierra que, según sus propias afirmaciones, permaneció durante siglos «sin luz alguna en los primores del arte». Como han señalado algunos investigadores para el caso novohispano, esa medida se antoja clave en entornos periféricos y debe resaltarse siempre, porque, al ser conscientes de ello, los maestros más notables de dichas regiones trabajaron bajo los imperativos del arte nuevo o buen estilo. Por eso mismo, salvando las distancias y los tiempos, nuestro autor encarna a la perfección

\footnotetext{
${ }^{6}$ Rodríguez González, Margarita: Juan de Miranda..., op. cit., pp. 11-20.

7 Cfr. AA. VV.: Lux nivariensis. La Real Sociedad Económica de Amigos del País de Tenerife en su 240 aniversario, La Laguna, 2017, pp. 77-96, con bibliografía previa.
} 


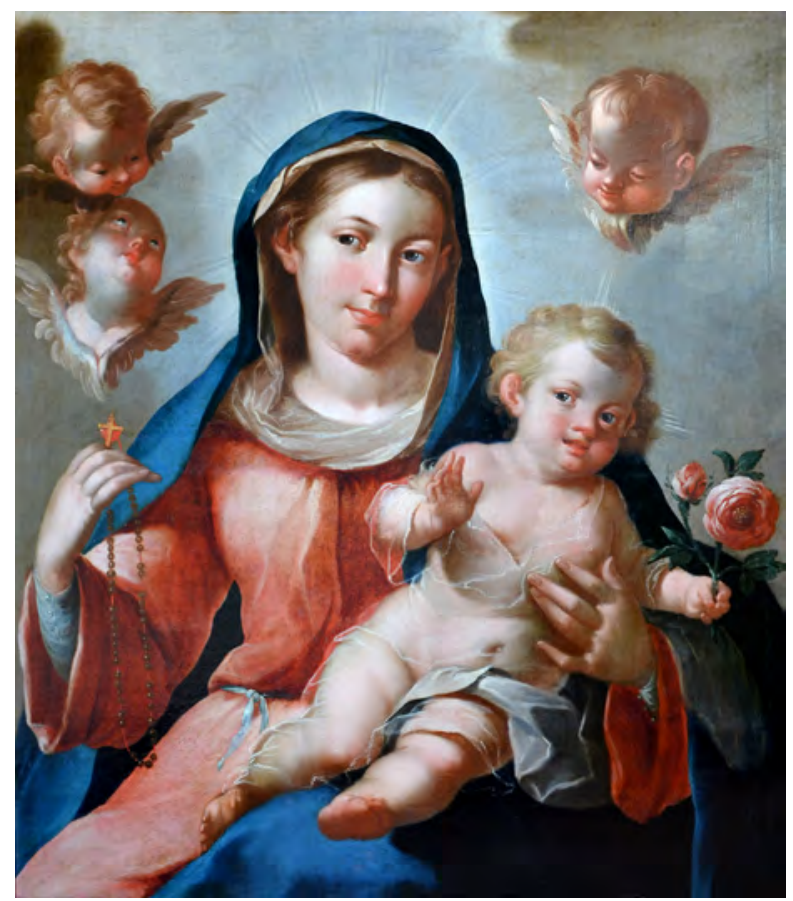

Fig. 1. Atribuido a Juan de Miranda: Virgen del Rosario. Colección particular, Puerto de la Cruz.

el rol de los creadores que reivindicaron la liberalidad de su oficio sin renunciar a prácticas heredadas del pasado ${ }^{8}$. Sólo así se explica, por ejemplo, el modo en que compuso sus primeros retratos ${ }^{9}$ o el valor concedido a la imagen sacra en un entorno proclive al reformismo borbónico, donde el arte $-y$ por añadidura el anhelo piadoso que subyace tras él con trasfondo político, determinante a veces- no escapaba a los planteamientos que defendieron eruditos, clérigos y otros hombres de cultura ${ }^{10}$.

Que un pintor como Miranda recreara escenas de ese tipo en el Archipiélago es ya un triunfo del ideario dieciochesco, aunque tal determinación puede someterse a múltiples puntos de vista. En un ensayo anterior tratamos ampliamente dicha

${ }^{8}$ Cfr. AA.VV.: Pintado en México. 1700-1790. Pinxit Mexici [catálogo de la exposición homónima], México-Los Ángeles, 2017.

9 Lorenzo Lima, Juan Alejandro: «De una pintura y su tiempo. José Jacinto de Mesa y Castilla, retratado por Juan de Miranda», Consejo Consultivo de Canarias. Fondo patrimonial, La Laguna, 2015, pp. 19-53.

10 Rodríguez González, Margarita: La pintura en Canarias durante el siglo XVIII, Las Palmas de Gran Canaria, 1986, pp. 294-368. 


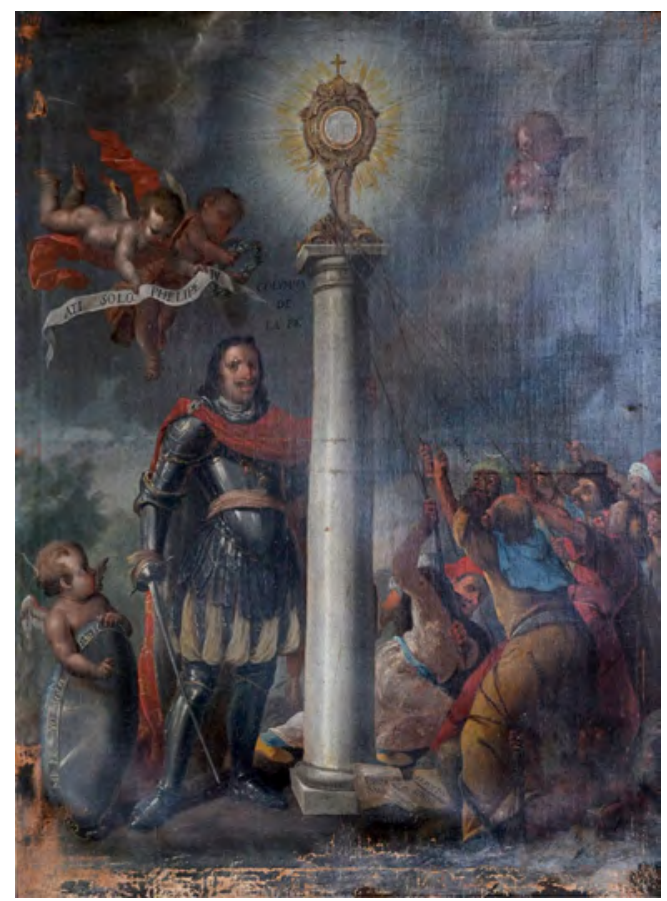

Fig. 2. Atribuido a Juan de Miranda: Felipe IV como columna de la fe y defensor de la Iglesia. Colección particular, La Orotava.

circunstancia ${ }^{11}$, llegando a la conclusión de que el artista manipuló toda clase de modelos o antecedentes figurativos para concebir en la mayoría de los casos una propuesta propia. Últimos hallazgos confirman la hipótesis de que fue un hombre culto e instruido, que supo moverse entre la tradición seiscentista y los nuevos postulados de la Ilustración. Así lo previene su elegante representación de la Inmaculada y España firmada en 1778 (parroquia de Nuestra Señora de la Concepción, Santa Cruz de Tenerife) y, sobre todo, una alegoría hasta el momento inédita que hemos localizado en Tenerife y representa al rey Felipe IV como pilar de la Iglesia, como su único defensor ante la herejía protestante (colección particular, La Orotava). Aunque preparamos ya un estudio exhaustivo sobre dicha obra ${ }^{12}$, sirve ahora para ejemplificar la ambivalencia de los lenguajes recurridos por el maestro y su afinidad con discursos propagandísticos que alentó la política del Antiguo Régimen [fig. 2].

${ }^{11}$ Lorenzo Lima, Juan Alejandro: Juan de Miranda. Reverso de un autorretrato, Islas Canarias, 2011.

${ }^{12}$ Lorenzo Lima, Juan Alejandro: «Religión y pintura alegórica. Ideario político en el arte canario a finales del Antiguo Régimen", en prensa. 
Precisamente, a ese Miranda y no al devoto pintor de las Inmaculadas que glosaron los biógrafos del siglo XIX tendremos que acudir en el futuro para atisbar la singularidad de su arte, porque, como demuestran las composiciones alegóricas o de mayor complejidad, a él no fueron ajenos planteamientos de alcance teórico y práctico. A ambos nos limitaremos en los epígrafes que siguen, ya que son necesarios a la hora de estudiar piezas conocidas y otras de gran atractivo que se dieron a conocer en los últimos años.

\section{NOVEDADES Y ATRIBUCIONES, EL DEBATE PERMANENTE DE «LO MIRANDESCO»}

Tras la publicación de una última monografía en 2011, son muchas las novedades que han concernido a la producción de Miranda en diverso modo y medida. Varias de ellas tienen que ver con el rescate de lienzos que se creían perdidos y con la restauración de otros bajo una metodología adecuada, aunque a priori resulta elogiable el esfuerzo seguido por instituciones locales para exponer creaciones suyas en museos y templos de diversas islas. De lo último hay pruebas sobradas, pues, por ejemplo, desde el verano de 2013 el museo de arte sacro de Teguise exhibe de forma permanente un amplio cuadro de altar: la Magdalena ungiendo los pies de Cristo, deudor de estampas grabadas e insólito por la ambientación procurada a una escena susceptible de interpretaciones dieciochescas. Fue pintado para que presidiese la ermita que el capitán Bernabé Antonio Camacho erigió junto a la hacienda familiar de Conil ${ }^{13}$, de modo que, tras largo tiempo fuera del culto, su exposición al público es una medida elogiable por varias razones. Gracias a ello constatamos que al pie dispone de una inscripción datada en 1794 y guarda relación con la oratoria sagrada, al resultar significativo el paralelismo existente entre la pintura y lo recogido por José de Viera y Clavijo (1731-1813) en un sermón sobre dicho pasaje del Evangelio que predicó en Madrid durante la Cuaresma de $1782^{14}$.

Años después, en marzo de 2017, se firmaba otro convenio por el cual la familia Valle Salas cedía a la parroquia de Teguise una representación de la Inmaculada que parece obra indudable del maestro ${ }^{15}$. Curiosamente, ya la habíamos identificado por medio de una fotografía en blanco y negro que integra los fondos de la fototeca de la Universidad de Sevilla, pero su ficha constata que al tiempo de

13 Rodríguez González, Margarita: «Lanzarote y Fuerteventura y la pintura canaria de la época Moderna", Actas de las IX jornadas de estudios sobre Fuerteventura y Lanzarote, Puerto del Rosario, 2000, t. II, pp. 13-32; Hernández Socorro, María de los Reyes: «El patrimonio pictórico de Lanzarote hasta 1900", Lanzarote y su patrimonio artístico, Arrecife, 2014, pp. 188-190, 213.

${ }^{14}$ Así lo hizo notar SÁnchez Rodríguez, Julio: «Los sermones de Viera y Clavijo», Estudios sobre Viera. Religión, familia, iconografía, emblemática, Islas Canarias, 2014, pp. 143-154.

15 "Teguise se hace con una de las joyas de la pintura canaria de Juan de Miranda", La Provincia. Diario de Las Palmas, Las Palmas de Gran Canaria, 25/3/2017, p. 20. 
reproducirla a principios del siglo xx era propiedad de Orestes Trujillo ${ }^{16}$. En cambio, no hemos tenido la misma suerte con otra Inmaculada de clara estirpe mirandesca que fue fotografiada entonces e incluyen los registros del mismo centro. Se trata de una pintura de tamaño medio que pertenecía a la colección de dońa Angustias Beltrán en Tenerife, aunque ignoramos su paradero actual ${ }^{17}$.

Amparándose en un convenio previo de colaboración con la Real Academia de Bellas Artes de San Fernando, la Casa de Colón exhibió durante varios meses de 2015 y 2016 el lienzo que figura a San Fernando recibiendo la embajada del rey de Baeza, obra de referencia obligada por el autorretrato que muestra al reverso (Academia de San Fernando, Madrid). Se trata del mismo trabajo que el autor presentó al concurso de la Academia en 1760 , cuya suerte posterior era conocida ${ }^{18}$. Tal acontecimiento brindaba una oportunidad irrepetible para aproximarnos a la plástica mirandesca y reivindicar su singularidad con un punto de vista múltiple, por lo que ello no pasó desapercibido en la prensa periódica ${ }^{19}$.

Ese hecho nos animó a volver sobre una pieza que identificamos años atrás y a valorar con nuevos bríos la dedicación de Miranda al género del retrato, revelando con ello algunos aportes significativos. A su pobre catálogo de «efigies personales» se sumaba entonces el pequeño retrato del médico Carlos Yánez de Barrios (Casa Museo Cayetano Gómez Felipe, La Laguna), acaso el mismo que algunos documentos refieren en $1763^{20}$, y otros de mayor tamańo conservados en Tenerife. Entre los últimos destacamos la representación del comerciante Esteban Dionisio Cambreleng (colección particular, Santa Cruz de Tenerife) y, sobre todo, las de Catalina Prieto del Hoyo y su hijo Melchor de Ponte y Prieto (colección particular, Garachico), siendo elogiable las últimas por el acabado técnico y el cosmopolitismo del que ambos personajes hacen gala gracias al atuendo, la pose y una cuidada ambientación dieciochesca ${ }^{21}$. A esa creciente nómina de retratos, de la que quizá convendría excluir algunos que se le atribuyen desde antiguo, se unieron luego la

${ }^{16}$ Biblioteca de la Universidad de Sevilla [BIB-US]: Fototeca. Registro 15362.

17 BIB-US: Fototeca. Registro 15364.

18 AA.VV.: Historia y alegoria: los concursos de pintura de la Real Academia de Bellas Artes de San Fernando (1753-1808), Madrid, 1994, pp. 77-87; Lorenzo Lima, Juan Alejandro: «Juan de Miranda...", art. cit., pp. 173-206.

${ }^{19}$ Cfr. «La Casa de Colón muestra la identidad de Juan de Miranda tres siglos después», La Provincia. Diario de Las Palmas, Las Palmas de Gran Canaria, 12/6/2015; «Juan de Miranda, el díscolo pintor», Canarias en hora [recurso web], 12/6/2015; «Un cuadro de Juan de Miranda viaja de Madrid a Gran Canaria, su isla natal», El Dia, Santa Cruz de Tenerife, 12/6/2015; "La pintura crucial de Juan de Miranda llega a Canarias», Canarias 7, Las Palmas de Gran Canaria, 17/5/2015; "Juan de Miranda. Claves para un encuentro en nuestro tiempo", Canarias 7, Las Palmas de Gran Canaria, 3/7/2016, entre otros.

${ }^{20}$ Gaviño de Franchy, Carlos: «Algunas consideraciones acerca de un pequeño retrato: el médico Carlos Yánez de Barrios y el pintor Juan de Miranda», Homenaje a la profesora Constanza Negrin Delgado, La Laguna, 2014, 249-275.

${ }^{21}$ Lorenzo Lima, Juan Alejandro: "A propósito de Juan de Miranda y el retrato del siglo xvin en Canarias. Nuevas atribuciones, nuevas ideas», Homenaje a la profesora..., op. cit., pp. 387-411. 
figuración de Francisco de Lugo y Viña (colección particular, La Orotava) y la del primer marqués de Las Palmas (colección particular, La Laguna), cuya notoriedad es mayor al reflejar variantes en torno a las cuales se concibieron habitualmente las representaciones masculinas ${ }^{22}$. De ello participa la efigie a gran tamaño de José Jacinto de Mesa y Castilla, firmada en 1759 y semejante a la del también regidor Baltasar Peraza de Ayala que sería ultimada un año después (ermita de la Trinidad, La Laguna). Su similitud explica que fueran confundidas en el pasado, aunque la compra de la primera por parte del Consejo Consultivo de Canarias alentó el estudio de ambas en $2014^{23}$.

Dichos retratos no son las únicas piezas que han incrementado el catálogo mirandesco. Las exposiciones temporales se revelaron años atrás como una oportunidad para divulgar o dar a conocer obras nuevas, destacando en ese sentido otra Inmaculada que pudo contemplarse en la muestra Creo, que la diócesis de Canaria organizó en 2013 (colección particular, Las Palmas). Allí se mostraba junto a piezas ya estudiadas de su autoría como la Expulsión del Paraíso (monasterio del Císter, Teror) o un elogiable San Miguel Arcángel (ermita de San Antonio, Las Palmas), aunque, en cambio, no nos parece creación suya el Cristo o Buen Pastor que le fue atribuido entonces ${ }^{24}$. Respecto a la Virgen, intuimos que se corresponde con la misma que Rodríguez González refería en 1986 como propiedad de un coleccionista capitalino $^{25}$. De no ser así, se trataría de una pieza inédita y algo convencional, cuyo interés estriba en que reproduce un grabado popular de finales del siglo XviII donde Juan Antonio Carmona (1740-1805) recreó un lienzo perdido del pintor Mateo de Cerezo (1637-1666 ${ }^{26}$ [figs. 3a y 3b].

La otra gran exposición organizada en Gran Canaria durante los últimos años, la que conmemoró en 2015 el bicentenario del fallecimiento de José Luján Pérez (1756-1815), trajo consigo una novedad inesperada para el catálogo de Miranda. En ella Hernández Socorro dio a conocer un Vía Crucis de pequeño formato y con 14 estaciones que conservaba inédito la iglesia de San José de las Vegas, en el municipio de Santa Brígida. Las obras que lo componen, de técnica suelta y algo abocetada, son un reclamo para estudiar el proceso creativo que siguió a menudo el artista y confirman su interés por la indefinición formal sin descuidar recursos

22 Gaviño de Franchy, Carlos: «Algunas consideraciones...», art. cit., pp. 269-273; LoRenzo Lima, Juan Alejandro: «El retrato en la producción pictórica de Juan de Miranda. Artificio e imagen para la sociedad de Canarias durante el siglo XviII", Anuario de Estudios Atlánticos, n. ${ }^{\circ} 62$ (2016), 32 pp.

${ }^{23}$ Lorenzo Lima, Juan Alejandro: "De una pintura...", art. cit., pp. 19-53.

${ }^{24}$ Cfr. AA.VV.: Creo [documental de la exposición homónima], Las Palmas de Gran Canaria, 2013.

${ }^{25}$ Rodríguez González, Margarita: La pintura..., op. cit., p. 341.

${ }^{26}$ La estampa fue extremadamente popular en tiempos de Miranda. Se conservan ejemplares de ella en la Calcografía Nacional [registro 3774], la Biblioteca Nacional [fondo reservado de Bellas Artes, INVENT/13175] y el Museo del Prado [número de catálogo G002626], entre otras instituciones. Cfr. Repertorio de grabados españoles en la Biblioteca Nacional, Madrid, 1981, p. 82/n. ${ }^{\circ}$ 1968-13; y Calcografía Nacional: catálogo general, Madrid, 2004, t. I, p. 97/n. ${ }^{\circ} 418$. 

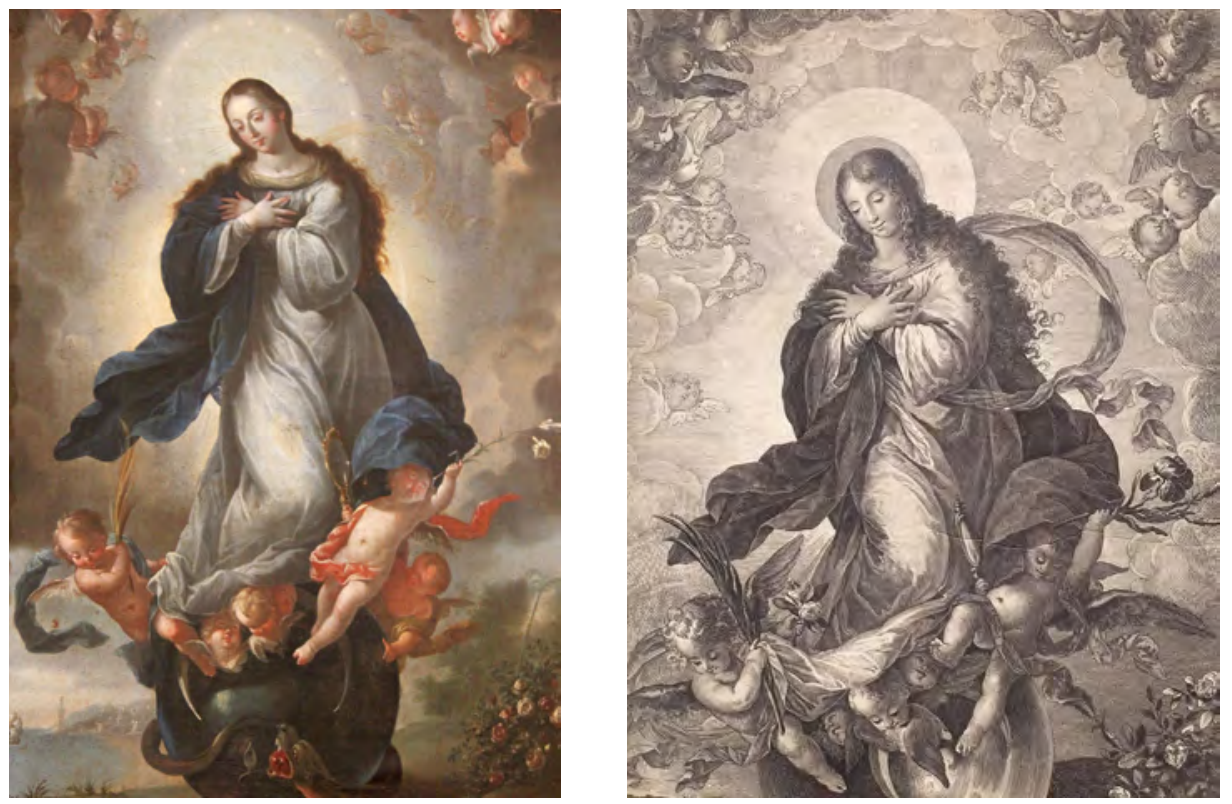

Figs. 3a. Atribuido a Juan de Miranda: Inmaculada. Colección particular, Las Palmas de Gran Canaria; y 3b. Juan Antonio Salvador Carmona: Inmaculada. Biblioteca Nacional de España, Madrid.

usuales como las concesiones al paisaje, la concentración de personajes con adecuado lenguaje gestual o, muy especialmente, la dislocación de planos buscando una profundidad que acentúan luces poco contrastadas ${ }^{27}$. Por el contrario, la Asunción que cuelga en la ermita del Espíritu Santo de Las Palmas y le fue atribuida entonces nos parece obra alejada de su estilo, resultando probable la adscripción a autores foráneos del siglo XVII ${ }^{28}$.

El trabajo de archivo también reveló novedades por último, ya que han podido documentarse varios lienzos del maestro. Así, al margen de lo señalado por Lavandera López para conocer el políptico de la parroquia de La Oliva ${ }^{29}$, resulta atractivo que obras de reciente atribución guarden relación con documentos muy diversos. Sirven de ejemplo en ese sentido sendas representaciones de San Agustín y

27 Hernández Socorro, María de los Reyes: «Un nuevo Vía Crucis de Juan de Miranda», José Luján Pérez. El hombre y la obra 200 años después [catálogo de la exposición homónima], Las Palmas de Gran Canaria, 2015, pp. 191-192, 225-227.

28 AA. VV.: José Luján Pérez. El hombre..., op. cit., p. 173.

${ }^{29}$ Lavandera López, José: «La iglesia de Nuestra Señora de Candelaria del lugar de La Oliva», La Oliva. La historia de un pueblo de Fuerteventura, La Oliva, 2011, pp. 180-182. 
Santa Ana que exhibe el retablo mayor de la ermita de San Roque en Valles de Ortega, acaso las mismas que Concepción Rodríguez vincula con Ana Cabrera (1719-1811). Debe tratarse de las creaciones de igual iconografía que dicha "devota» citaba en un codicilo de 1810, aunque su voluntad era colocarlas en un retablo que no llegó a erigirse en la parroquia de Antigua ${ }^{30}$. Este caso demuestra que no es fácil vincular pinturas conservadas con noticias o testimonios de época, puesto que habitualmente las citas disponibles son ambiguas e inconexas. De ahí que últimas publicaciones se limiten a resaltar el protagonismo del artista y a confirmar lo expuesto años antes por otros investigadores, porque, a pesar de los esfuerzos realizados, no siempre pueden documentarse trabajos ya conocidos o aportar algo nuevo a partir del acabado que manifiestan. Pese a ello, el análisis de las fuentes grabadas que manejó Miranda es un aspecto indispensable para advertir el alcance de su arte. Por eso mismo resultan esclarecedores algunos estudios que ofrecen una visión de conjunto sobre el particular ${ }^{31}$, así como otros que confirman la vinculación de nuestro artífice con el grabado catalán en tiempos de Ignasi Vals (1726-1764) o con estampas populares en Madrid y el Levante cuando mediaba el siglo XVIII ${ }^{32}$.

La nómina de cuadros a incluir en el catálogo de Juan de Miranda tampoco deja de aumentar, sobre todo si nos limitamos a escenas con temática religiosa. De ahí que, por ejemplo, se haya señalado su autoría para una representación al uso de Santo Domingo de Guzmán (ermita del Socorro, Tegueste) ${ }^{33}$ y un martirio de Santa Catalina que subsiste junto a los retratos de Catalina Prieto y Melchor de Ponte (colección particular, Garachico), antes aludidos ${ }^{34}$. En colecciones particulares de Tenerife y Gran Canaria hemos localizado algunos trabajos suyos que deberán estudiarse en el futuro, pero conviene insistir en una inédita e interesante Adoración de los Pastores (colección particular, Santa Cruz de Tenerife). Su solvencia plástica y figurativa queda fuera de dudas por el detenimiento puesto a la hora de recrear ciertos personajes, proclives siempre a la descripción bajo una técnica precisa y meticulosa [fig. 4]. Además, la reiteración de los temas y el manejo de los mismos grabados explican que esa obra guarde relación con otras representaciones del mismo asunto. Una de ellas, ahora en paradero desconocido, fue vendida en la galería Durán de Sevilla a finales de 1995, por lo que tal hecho sugiere que fue pintada allí durante los años del periplo peninsular y prueba sin querer que la definición de motivos

30 Concepción Rodríguez, José: «Doña Ana de Cabrera: un personaje singular en Fuerteventura (siglos XVIII-XIX)», XV jornadas de estudios sobre Fuerteventura y Lanzarote, Puerto del Rosario, 2016, pp. 152-153, 158-159.

${ }_{31}$ MuÑIz MuÑoz, Ángel: «La ilustración del libro como generador de modelos. Pintores canarios del Barroco y su relación con el grabado", Anuario de Estudios Atlánticos, n. ${ }^{\circ} 61$ (2015), 19 pp.

32 Lorenzo Lima, Juan Alejandro: «El retrato...», art. cit., pp. 25-26; Muñız Muñoz, Ángel: «Grabados del siglo Xviı en la obra de Juan de Miranda. A propósito de la Virgen de los Dolores y San Nicolás de Bari», Estudios Canarios. Anuario del Instituto de Estudios Canarios, n. ${ }^{\circ} 57$ (2013), pp. 145-156.

33 Rodríguez González, Margarita: «Santo Domingo de Guzmán», Patrimonio religioso de la Villa de Tegueste, Tegueste, 2014, pp. 170-171/n. ${ }^{\circ} 4.1 . X$.

34 Lorenzo Lima, Juan Alejandro: «A propósito...», art. cit., pp. 399-401. 


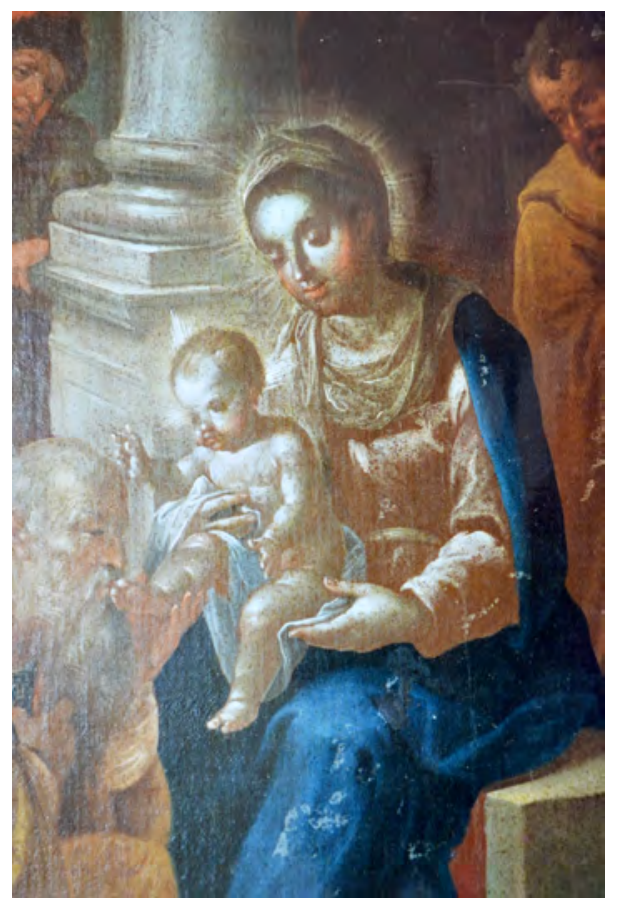

Fig. 4. Atribuido a Juan de Miranda: Adoración de los Reyes Magos [pormenor]. Colección particular, Santa Cruz de Tenerife.

habituales en su catálogo sería una consecuencia más de esa trascendental etapa de estudio y formación ${ }^{35}$.

Precisamente, otra de las oportunidades exploradas en los últimos ańos para conocer obras nuevas del artista guarda relación con el comercio del arte. El caso de la Virgen de Rosario que centra este ensayo es un testimonio palpable de ello [fig. 1], aunque no el único. Al conocerse ya la producción de Miranda en ambientes peninsulares resulta fácil el vínculo de diversos lienzos con su estilo y forma de pintar, porque, por ejemplo, años atrás pudo adquirirse en Valencia una Inmaculada que perteneció al coronel Manuel Montesinos (1796-1862) (colección particular, La Laguna); y del mismo modo constatamos ahora que una amplia Coronación de la Virgen publicada en 2011 continúa expuesta en galerías madrileñas como cuadro de atribución segura a nuestro artista (Antigüedades Juan Salas, Madrid). Subastas Alcalá vendió en diciembre de 2015 un lienzo de pequeño formato que le fue adscrito

35 Díaz Padrón, Matías: «Juan de Miranda en Sevilla», La Provincia. Diario de Las Palmas, Las Palmas de Gran Canaria, 11/4/2016, p. 54. 
entonces y representa a San Juan Nepomuceno (colección particular, Madrid) ${ }^{36}$, pero corresponde mejor con el trabajo de algún discípulo o continuador de su estilo. Lo mismo cabría decir sobre una Inmaculada de tamaño medio comprada en marzo de 2017 (colección particular, Santa Cruz de Tenerife), cuya primera catalogación era «escuela española del siglo XVIII" ${ }^{37}$. Antes de la adquisición algunos investigadores repararon ya en su débito mirandesco, aunque ni la técnica ni la definición de ciertos detalles del personaje principal, especialmente del rostro, avalan una atribución certera al maestro ${ }^{38}$.

En cambio, no sucede así con otra Inmaculada de mayor formato que sigue a la venta en Cataluña (Antigüedades Castellarnau, Tarragona) y de la que ignoramos su origen, última procedencia y datación. Un estudio de Muñiz Muñoz defiende la autoría atendiéndose a cuestiones formales y compositivas que no generan dudas ${ }^{39}$, pero esta obra en concreto resulta de interés por algunos rasgos que singularizan al arte de Miranda durante los ańos del periplo peninsular. Por eso mismo el angelito de cuerpo entero y la figura mariana tienden a un sutil alargamiento del canon, algo que enmascara el sentido dinámico de los textiles, un cromatismo vivo, el lenguaje gestual y la misma ambientación que da cabida a varios querubines junto a símbolos apocalípticos y emblemas derivados de la letanía lauretana, los últimos de fácil comparativa con pinturas conservadas en el Archipiélago. Además, el suave colorido y la destreza técnica ponen de relieve la sofisticación alcanzada por Miranda antes de 1770, fecha en torno a la que podría datarse la Virgen del Rosario que le atribuimos ahora y se estudiará en el siguiente epígrafe.

\section{UNA OBRA NUEVA CON ORIGEN EN EL LEVANTE}

Lo expuesto anteriormente confirma que el catálogo de un artista de larga trayectoria como Miranda es susceptible de ampliaciones y correcciones, a veces inesperadas. A su nómina de obras atribuidas sumamos ahora un lienzo muy revelador, del que nada se ha publicado en el medio académico o científico [fig. 1]. Tuvimos noticia de él gracias al galerista madrileño José de la Mano, quien advirtió en algunos detalles -y particularmente en los ángeles y en la figura del Niño Jesús, de indudable parecido con pinturas suyas de Canarias- los modos de Juan de Miranda. Luego, tras el estudio pertinente y una ligera limpieza, fue adquirida por un coleccionista de Tenerife, en cuyo poder se encuentra desde entonces. Su recuperación es una noticia significativa y, a nuestro modo de ver, un aliciente oportuno para profundizar en la trayectoria peninsular del autor.

36 Subastas Alcalá. Subasta de diciembre de 2015 [n. ${ }^{\circ}$ 79], lote 804.

37 Abalarte subastas. Subasta de febrero de 2017, lote 757.

38 Agradecemos a Ángel Muñiz que nos comunicara entonces la existencia de esta pintura, estudiada igualmente por él.

39 Muñız Muñoz, Ángel: «Una posible Inmaculada de Juan de Miranda localizada en Tarragona", Homenaje a la profesora..., op. cit., pp. 443-455. 
Al margen de esa cuestión afectiva o interesada, la pintura se convierte en pieza clave por otras razones. De entrada resulta sugestiva por la firma que muestra al reverso del lienzo ${ }^{40}$ y la localización previa en Alicante, porque, tal y como comunicaron sus últimos poseedores, colgó durante siglos en un domicilio importante de dicha ciudad. Ello lo vincula de una u otra forma con la trayectoria del autor, al ser precisamente Alicante la única localidad peninsular donde se documenta su existencia durante la década de 1760. Consta que pintó allí sendas representaciones de San Nicolás de Bari y del Milagro de las Santas Faces para decorar el oratorio del palacio consistorial ${ }^{41}$; y aunque no abundan noticias al respecto, hemos constatado que residía en esa ciudad hasta al menos julio de 1767 , pues reclamó entonces el pago de 40 libras valencianas que le adeudaban por el trabajo ya realizado. A pesar de este hecho, su estancia en otros puntos del Levante como Murcia o Valencia resulta probable si atendemos a las cualidades que mostraron luego obras notables y al vínculo que varios puertos de la región sostuvieron con la plaza de Orán, donde el artista estuvo recluido desde al menos 1758. Tal coyuntura permitió vincular con su arte un cuadro de altar conservado en Murcia y otros provenientes de ciudades próximas, aunque esa circunstancia no despierta todavía una opinión unánime. El asunto tan controvertido de las atribuciones vuelve a cobrar sentido, pero en este caso sirve también para insistir en ideas expresadas a partir de las creaciones de ese tiempo que le adscribimos antes ${ }^{42}$.

La nueva Virgen del Rosario es una representación convencional, a buen seguro deudora de pinturas y estampas previas. Sin embargo, como es habitual en otros trabajos de Miranda, no parece atenerse a un único patrón o modelo conocido. En ella, pese al convencionalismo de representar a la Virgen con el Niño de medio cuerpo y frente a un celaje con cabezas de querubín, afloran detalles que pueden localizarse en grabados devocionales y en estampas cultas como varias láminas de los hermanos Klauber que ilustran la letanía de Francisco Javier Dornn, recurrida a veces por nuestro artífice ${ }^{43}$. Esa circunstancia no esconde una voluntad de reafirmar los rasgos estéticos del siglo XviII por la pulcritud de su técnica o la viveza del colorido, algo que, al margen de otras interpretaciones posibles, vincula esta «imagen piadosa» con los modos seguidos por maestros peninsulares y novohispanos contemporáneos. Sirvan de muestra para ello el modo en que la Virgen sostiene al rosario y al Niño con sendas manos, así como la forma en que el último quedó dispuesto en

${ }^{40}$ Donde se lee con facilidad «Ness. fecit», apunte enigmático que puede aludir al nombre del artífice como «Joanes». Agradecemos a José de la Mano y a otros compañeros de la Universidad de Valencia las opiniones brindadas para estudiar esta extrańa firma, no vinculable con maestros contemporáneos.

${ }^{41}$ Hernández Guardiola, Lorenzo: Pintura decorativa barroca en la provincia de Alicante, Alicante, 1990, t. III, pp. 83-89.

${ }^{42}$ Lorenzo Lima, Juan Alejandro: Juan de Miranda..., op. cit., pp. 45-89.

43 Copió de modo literal la figura central de una lámina incluida en las ediciones españolas de Dornn para componer la Virgen del Rosario con el Niño Enfermero (colección particular, Las Palmas de Gran Canaria). 
un lateral con forzado escorzo o alarde perspectívico. No insistiremos más en dicha cuestión al resultar obvia la comparativa, pero justamente en esos aspectos afines, en los elementos repetidos una y otra vez por el autor, se encuentran rasgos de lo que valoramos ahora como arte de Juan de Miranda durante los años peninsulares.

Sorprende, por ejemplo, el detenimiento puesto en un celaje al que dan forma suaves degradaciones de grises, verdes y azules, habituales en su producción posterior; y del mismo modo, las cabezas de querubín -y especialmente la que mira a lo alto en el lado izquierdo, un auténtico cuadro dentro del cuadro- resultan parangonables con algunas contenidas en representaciones suyas de tipo hagiográfico e inmaculista. Detalles secundarios como las manos de la Virgen con sus dedos finos o la rosa que porta el Niño se prestan también a una comparativa fácil, siendo elocuente el paralelismo que dicho atributo de iconografía mariana describe respecto a lo contemplado en las Inmaculadas de la catedral de La Laguna y la parroquia matriz de La Orotava. No obstante, donde se observa un paralelismo mayor con la producción mirandesca es en la figura del Niño Jesús, cuya anatomía rolliza y los rasgos fisonómicos remiten directamente a uno de los ángeles contemplados en la Inmaculada aparecida por último en Tarragona y, entre otros, al Infante que San José porta en sus manos cuando fue efigiado de medio cuerpo y con inusual fondo negro (colección particular, La Orotava). Comparten todos ellos un mismo sentido del volumen a la hora de conformar las cabezas, gracias a las orejas con ligero despunte en sus extremos, el cabello claro y los rasgos que dan cabida a una boca bien definida con labios pequeños y carnosos, amplios mofletes de tez rosácea, nariz de suave proporción, cuencas orbitales marcadas y ojos vivos por el poco resalte conferido a los párpados.

Dos elementos más resultan de interés en la obra y dejan entrever la evolución que el arte mirandesco tuvo luego, porque, de consensuarse la propuesta que defendemos, esta Virgen del Rosario sería una referencia válida a la hora de atribuir o comparar creaciones realizadas por el artífice en torno a 1770. Lo primero tiene que ver con la técnica y el color, ya que, sin contradecir su modo de aplicar el pigmento sobre el lienzo con habilidad y precisión, de forma algo indefinida e intuitiva, genera soluciones elogiables por la acción de barnices unificadores y poco contrastados que la tela conserva extrañamente bien. Al igual que sucede en otras pinturas de pasado levantino que le hemos atribuido, en esta recreación de Alicante afloran colores brillantes y armónicos para generar una idea unitaria de los elementos tan distintos que integran la composición y, sin duda, aproximar su acabado al arte de autores que tuvieron éxito en la región como José Vergara (1726-1799) o José Camarón (1731-1803), por citar sólo los más significativos. Lo avalan así oportunos toques de pincel recurriendo a los blancos de costumbre o el modo en que se apuran las carnaciones, tendentes a colores claros con habituales sonrosados que definen los perfiles extremos, los labios, las mejillas y los bordes de las cuencas orbitales. En cualquier caso, el resultado final no dista de los mejores trabajos del artista y confirma que durante los años del periplo peninsular Miranda forjó el estilo maduro que aduce este simulacro.

Tal circunstancia es contrastable con el modo en que se conciben otros detalles. Sirvan de ejemplo en ese sentido el fino traje del Niño o el atuendo mariano 
que integran camisa inferior de tonos claros, túnica rosa recogida al talle con cinta celeste, toca blanca y manto de intenso azul, siendo comparable el último con el que muestran muchas Inmaculadas suyas. Lo más desconcertante de la obra es el rostro de la Virgen con perfil de formas angulosas en torno al mentón, ya que, puestos a establecer comparativas, no encuentra una relación fácil con la pintura realizada a posteriori por Miranda; $y$ aunque ese hecho es cuestionable, intuimos que resulta clarificador para comprender la evolución de un artista que valora nuevas referencias formales y define su lenguaje plástico lejos del Archipiélago. De este modo se explican las diferencias perceptibles en cuadros que vinculamos con el periplo peninsular, porque, si gracias a algunos pormenores resultan piezas de adscripción indudable, otros generan dudas y remiten a un creador heterogéneo en sus presupuestos formales. Para percatarnos de ello basta reparar en los ángeles que la Inmaculada ya citada de Montesinos muestra en un lateral (colección particular, La Laguna) o en los ángeles inferiores y en los personajes de la Trinidad que integran la amplia Coronación de la Virgen (Antigüedades Juan Salas, Madrid), aunque, puestos a especular, resulta atractiva la hipótesis de que esos y otros componentes corresponden a un maestro que se siente seguro de su arte e intenta aproximarlo a cuanto conoció en una región de larga tradición pictórica como el Levante.

Sea como fuere, todavía es pronto para emitir hipótesis concluyentes sobre ese particular y cuanto deriva de él en clave estética o formal. El debate queda abierto y pinturas como la que nos ocupa de Alicante, un testimonio clave e inesperado en nuestro tiempo, ponen de relieve que desconocemos muchos pormenores para desentrañar la trayectoria de quien se convirtió por méritos propios en el mejor intérprete de la plástica canaria durante el Antiguo Régimen. Ante ello, no queda otra salida que seguir investigando y proponer correlatos pictóricos con los que comprender mejor un episodio clave de la producción mirandesca. 
